\title{
Editors' Editorial
}

Launching a new journal is not without hazard. The Editorial Board of Veterinary and Comparative Orthopaedics and Traumatology is, nevertheless, committed to the production of a journal of high scientific content which, it is hoped, will fill a need and also appeal to orthopaedic and trauma surgeons dealing with human patients as well as the various other animal species.

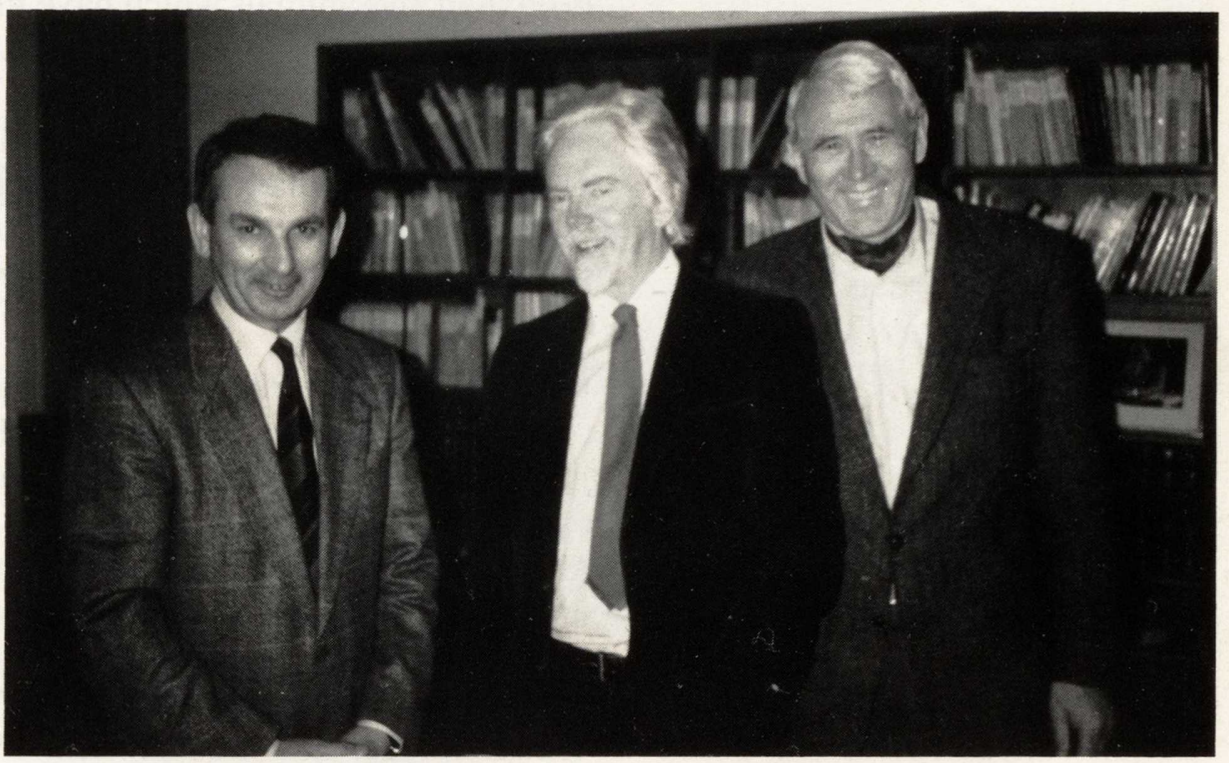

D. Bergemann (from Schattauer), G. Sumner-Smith, W. D. Prieur (editors).

It is planned that each edition will publish articles in the following categories:

editorial historical notes, invited review articles, research papers, surgical techniques and surgical reports, trauma and critical care research and reports, scientific and non-scientific Letters to the Editor, reviews of recently published learning material, a literature catalogue as well as news of the "European Society for Veterinary Orthopaedics and Traumatology" and the "Veterinary Orthopaedic Society".

In keeping with its aim to publish only scientifically acceptable articles, the Board requires that manuscripts be submitted to three referees and the opinion of the majority of the referees shall prevail.

Correspondence should be directed to the Editor-in-Chief who invites suggestions, criticism and papers from colleagues in both the medical and veterinary professions.

\section{G. Sumner-Smith}

T. D. Braden

W. D. Prieur 